\title{
STUDI KESESUAIAN RUANG BENGKEL KERJA KAYU PROGRAM KEAHLIAN KONSTRUKSI KAYU BERDASARKAN PERMENDIKNAS NOMOR 40 TAHUN 2008 DI SMK N 5 SURAKARTA
}

\author{
Kurnia Aprilliany ${ }^{1}$, Roemintoyo ${ }^{2}$, Budi Siswanto ${ }^{2}$ \\ Email: kurniaaprilliany@gmail.com
}

\begin{abstract}
ABSTRAK
Tujuan dari penelitian ini adalah untuk mengetahui kesesuaian ukuran luas bengkel kerja kayu berdasarkan Permendiknas No. 40 Tahun 2008, meninjau tata letak peralatan dan perabotan di ruang bengkel kerja kayu mesin terkait dengan alur kerja praktik yang sistematis, dan mengetahui kenyamanan pengguna dengan desain ruang bengkel kerja kayu yang ada. Hal ini diharapkan dapat mendukung pengembangan ruang bengkel kerja kayu agar memberikan kenyamanan bagi penggunanya. Penelitian ini merupakan jenis penelitian kualitatif. Data yang diperoleh berupa data primer dan data sekunder, dengan teknik pengambilan sampel berupa snowball sampling. Sedangkan metode pengumpulan data dilakukan dengan cara wawancara, observasi, dan dokumentasi. Teknik analisis data menggunakan model analisis interaktif dengan tahapan: pengumpulan data, reduksi data, penyajian data, dan penarikan kesimpulan atau verifikasi. Hasil dari penelitian ini adalah (1) Luas bengkel kerja kayu belum memenuhi standar Permendiknas No.40 Tahun 2008, karena jumlah peserta didik yang menggunakan ruang bengkel kayu melebihi kapasitas yang tercantum; (2) Tata letak peralatan dan perabotan di ruang bengkel kerja kayu belum sesuai dengan alur kerja praktik, dikarenakan terdapat kegiatan yang dilakukan diluar ruang bengkel sehingga membuat pekerjaan seperti sudah sesuai dengan alur kerja praktik kayu; (3) Desain ruang dan tata letak peralatan/perabotan belum memberikan kenyamanan bagi penggunanya, dan dalam aspek ketinggian meja kerja pada mesin sudah dirasa nyaman.
\end{abstract}

Kata kunci: luas, alur kerja praktik, ruang bengkel kerja kayu, kenyamanan

\footnotetext{
${ }^{1}$ Mahasiswa Program Studi Pendidikan Teknik Bangunan FKIP UNS

2 Pengajar Program Studi Pendidikan Teknik Bangunan FKIP UNS
} 


\title{
A STUDY OF SUITABILITY OF WOOD WORKSHOP IN WOOD CONSTRUCTION MAJOR BASED ON THE NATIONAL EDUCATION'S MINISTRY'S REGULATION (PERMENDIKNAS) NO. 40/2008 IN SMK N 5 SURAKARTA
}

\section{Kurnia Aprilliany ${ }^{1}$, Roemintoyo ${ }^{2}$, Budi Siswanto ${ }^{2}$ Email: kurniaaprilliany@gmail.com}

\begin{abstract}
The objectives of this study are to identify the suitability of wood workshop's area size based on National Education's Ministry's regulation (Permendiknas) No.40/2008, to review tools and furnishing layout in the machinery wood workshop related to systematic practice workflow, and to discover user's comfort in terms of the existing wood workshop design. It is expected to enhance the development of wood workshop to provide comfort for its users. The study belongs to qualitative research. The obtained data were primary data and secondary data by snowball sampling as the sampling technique. Meanwhile, the data collection methods used interviews, observation, and document study. The data analysed technique employed interactive analysis model using these steps: collecting data, reducing data, presenting data, and drawing conclusions or verification. The results of the study indicated that (1) the area of wood workshop were not yet the standards of Permendiknas No.40/2008, because the quantity of students using the wood workshop space exceeds the capacity listed; (2) the layout of tools and furnishing did not fulfill the appropriateness of practice workflow because there were some activities done outside the workshop, as if the works fit the practice workflow; (3) the design of room and tools/furnishing layout did not provide the comfort yet for its users, but the comfort has been obtained from the work table height toward machine.
\end{abstract}

Keywords: size, practice workflow, wood workshop, comfort

\footnotetext{
${ }^{1}$ Student of Building Engineering of Education FKIP UNS

${ }^{2}$ Lecturer of Building Engineering of Education FKIP UNS
} 


\section{PENDAHULUAN}

Pendidikan sangat penting untuk meningkatkan kualitas sumber daya manusia, dan salah satu lembaga pendidikan di Indonesia adalah SMK. Oleh karena itu SMK diharuskan mempunyai fasilitas praktik yang selalu mengikuti perkembangan teknologi sehingga dapat mendukung pelaksanaan kompetensi yang ditergetkan dalam kurikulum. Fasilitas praktik meliputi sarana dan prasarana yang ada didalamnya. Sarana yang dimaksud adalah ruang bengkel atau laboratorium.

Terdapat standar yang mengatur mengenai sarana dan prasarana yang ada di SMK yaitu Permendiknas No 40 Tahun 2008. Standar ini diharapkan agar dapat mempermudah proses pembelajaran atau kegiatan praktik, sehingga kualitas lulusan SMK akan menjadi lebih baik.

Penelitian ini dilakukan agar dapat menggambarkan seberapa jauh kesesuaian ruang bengkel kerja kayu yang ada di SMK N 5 sekarang dengan standar sarana dan prasarana, sehingga dapat meminimalisir masalah yang bisa terjadi pada saat kegiatan praktik berlangsung, diantaranya:

1. Ruang bengkel kayu tangan yang digunakan sebagai ruang pembelajaran.

2. Ruang bengkel kayu mesin yang tidak nyaman karena tata letak mesin yang berdekatan.

3. Kelebihan (overload) mesin.

4. Kapasitas ruang tidak sesuai dengan kapasitas peserta didik.

5. Kurangnya ruang untuk kegiatan praktik sehingga peserta didik melakukan praktik diluar ruangan dengan sikap kerja yang tidak nyaman.

Berdasarkan penjelasan meng-enai kondisi tersebut, maka mendasari dilakukannya penelitian tentang luas ruang bengkel kerja kayu, tata letak peralatan dan perabotan yang sesuai dengan alur kerja praktik yang sistematis, dan kenyamanan bagi penggunanya khususnya di SMK Negeri 5 Surakarta, dengan judul "Studi Kesesuaian Ruang Bengkel Kerja Kayu Program Keahlian Konstruksi Kayu Berdasarkan Permendiknas No.40 Tahun 2008 di SMK N 5 Surakarta".

\section{METODE PENELITIAN}

Penelitian berlokasi di SMK Negeri 5 Surakarta, khususnya di bengkel kerja kayu Jurusan Teknik Konstruksi Kayu. SMK N 5 merupakan salah satu SMK di Surakarta yang memiliki Program Keahlian Teknologi Konstruksi dan Properti (Bangunan). Sekolah ini juga sudah terdaftar sebagai sekolah adiwiyata dan tersertifikasi ISO oleh lembaga TUV Rheinland Group.

Lalu, penelitian ini menggunakan metode kualitatif pendekatan deskriptif yang bertujuan untuk memperoleh informasi mengenai keadaan saat ini, dan melihat kaitannya dengan fokus penelitian sebagai berikut: Ukuran luas ruang bengkel kerja kayu, Tata letak peralatan dan perabotan di ruang bengkel, dan Desain ruang dan tata letak peralatan/perabotan bengkel.

Data dalam penelitan ini meliputi data primer (hasil wawancara dan observasi) dan data sekunder (dokumen luas bengkel kerja kayu, standar sarana dan prasarana yang digunakan untuk SMK, khususnya program keahlian Teknik Bangunan, dan dokumen-dokumen lain yang terkait dengan ruang bengkel kerja kayu.). Sumber data atau informan yang dipilih meliputi:

1. Ketua Bengkel;

2. Guru mata pelajaran praktik;

3. Guru mata pelajaran praktik yang telah pensiun;

4. Teknisi bengkel;

5. Bagian Sarana dan Prasarana;

6. Peserta didik yang mengikuti mata pelajaran praktik;

7. Serta dokumen yang berkaitan dengan ruang bengkel kerja kayu.

Penelitian menggunakan satu jenis sampling, yaitu Snowball sampling, sehingga kebutuhan informan dapat berkembang sesuai dengan kebutuhan peneliti, sampai informasi yang didapatkan sudah dirasa cukup. Dan untuk teknik pengumpulan data berupa wawancara, observasi/ pengamatan, dan dokumentasi.

Teknik uji kredibilitas data menggunakan triangulasi sumber dan teknik. Triangulasi sumber meng-gunakan lebih dari satu sumber, kemudian data yang didapatkan dari berbagai sumber tersebut dicocokkan dan dibandingkan, sedangkan 
sumber yang dimaksud adalah: kepala bengkel, guru mata pelajaran praktik kayu, toolman, bagian sarpras, peserta didik, dan guru yang telah pensiun.

Lalu untuk triangulasi teknik dilakukan dengan cara mengecek data kepada sumber data yang sama dengan teknik yang berbeda, teknik dalam pengumpulan data yang dimaksud adalah wawancara, observasi, dan dokumentasi.

Teknik analisis data menggunakan model analisis interaktif seperti yang dikembangkan oleh Miles and Huberman (1984). Dapat dilihat pada gambar dibawah ini:

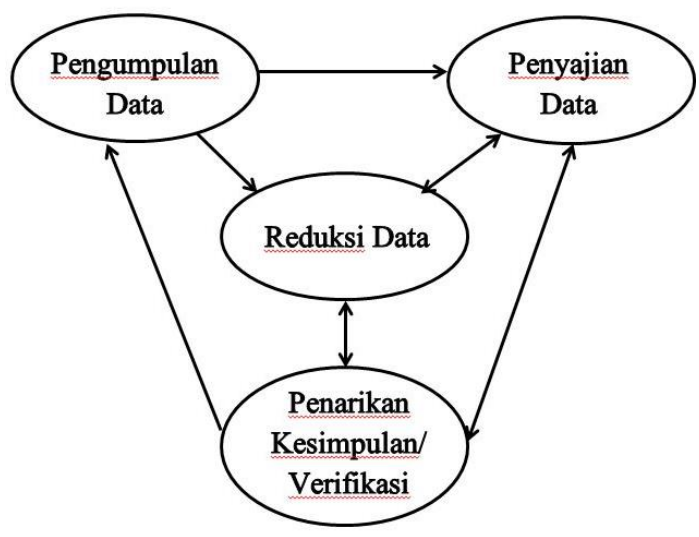

(Sumber : Sugiyono, 2010)

Gambar 1. Komponen analisis data

Dengan tahapan sebagai berikut:

1) Pengumpulan data.

Dalam tahap ini peneliti mencatat, menyalin, merekam, dan mendokumentasikan semua data yang sesuai dengan hasil wawancara. observasi, dan dokumentasi secara objektif di lapangan. Pada teknik wawancara peneliti akan menggunakan alat bantu berupa perekam suara agar memudahkan proses analisis.

2) Reduksi data.

Semakain lama peneliti berada di lokasi penelitian, maka data yang didapat akan semakin banyak dan berkembang, sehingga mengharuskan peneliti melakukan reduksi data. Reduksi data merupakan proses pemilihan data yang dianggap penting, merangkum, memfokuskan pada inti permasalahan, dan membuang data yang tidak penting yang diambil dari catatan-catatan di lapangan, dalam hal ini peneliti menggunakan alat bantu tabel. Dalam mereduksi data, peneliti juga dipandu oleh tujuan penelitian, dengan demikian peneliti dapat dengan mudah mengambil gambaran dengan jelas mengenai permasalahan, dan dapat mempermudah proses verifikasi kesimpulan.

3) Penyajian data.

Langkah selanjutnya yaitu penyadian data, penyajian data merupakan rangkaian informasi yang tersusun dari data yang telah direduksi dan memberikan kemungkinan untuk mengambil kesimpulan. Penyajian data akan memudahkan peneliti dalam memahami apa yang terjadi di lapangan, sehingga memudahkan untuk menentukan langkah selanjutnya. Penyajian data dalam penelitian ini dalam bentuk kualitatif.

Data yang telah didapatkan akan disusun menjadi deskripsi atau teks yang bersifat naratif berdasarkan inti atau tema permasalahan. Namun dapat pula didukung dengan berbagai jenis gambar, skema, tabel, dan lain-lain sebagai pendukung.

4) Penarikan kesimpulan atau verifikasi.

Tahap terakhir adalah peneliti melakukan penarikan kesimpulan. Namun, kesimpulan yang ada merupakan kesimpulan sementara yang kemungkinan dapat berubah jika tidak ada bukti yang kuat, oleh karena itu sebelum melakukan penarikan kesimpulan peneliti harus memverifikasi semua data yang telah direduksi dan di sajikan sebelumnya. Kemudian data tersebut disusun secara sistematis.

Dan tahapan prosedur penelitian meliputi:

1. Persiapan.

a. Pengajuan judul penelitian.

b. Menyusun proposal penelitian.

c. Melaksanakan seminar proposal.

d. Mengurus ijin penelitian

e. Menyusun instrument pengumpulan data

2. Pengumpulan data.

a. Pengumpulan data dengan menggunakan beberapa teknik, yaitu 
wawancara, observasi, dan dokumen atau arsip.

b. Membuat catatan lapangan dan transkrip hasil wawancara dengan informan.

c. Memilih dan merangkim data yang sesuai dengan rumusan dan tujuan penelitian.

3. Pengujian kredibilitas data.

Menguji kredibilitas data dengan menggunakan triangulasi sumber dan triangulasi teknik yaitu data yang digunakan lebih dari satu sumber, dan dilakukan dengan teknik yang berbeda kemudian data tersebut dicocokkan dan dibandingkan.

4. Analisis data.

a. Menentukan teknik analisis data yang sesuai dengan metode penelitian, meliputi pengumpulan data, reduksi data, penyajian data, dan penarikan kesimpulan.

b. Menganalisis lebih lanjut penyajian data lalu dibandingkan dengan temuan dilapangan.

c. Selanjutnya merupakan proses verifikasi data dan pengayaan dengan mengkonsultasikan dengan dosen pembimbing.

d. Membuat kesimpulan sesuai dengan hasil penelitian.

5. Penyusunan laporan penelitian.

a. Penyusunan laporan awal.

b. Meninjau laporan yang telah disusun dengan dosen pembimbing.

c. Melakukan perbaikan sesuai dengan hasil konsultasi dengan dosen pembimbing.

d. Penyusunan laporan akhir.

e. Membuat kesimpulan hasil penelitian.

\section{HASIL PENELITIAN DAN \\ PEMBAHASAN}

Hasil penelitian dan Pembahasan disajikan dalm 3 fokus penelitian, meliputi:

1. Ukuran luas ruang bengkel kerja kayu Program Keahlian Konstruksi Kayu,
Dalam Permendiknas No.40 Tahun 2008 ditentukan standar luas ruang bengkel kerja kayu untuk SMK Program Keahlian Konstruksi Kayu, yaitu luas keseluruahan adalah $304 \mathrm{~m}^{2}$, meliputi:

a. Area kerja kayu tangan $128 \mathrm{~m}^{2}$

b. Area kerja mesin kayu $64 \mathrm{~m}^{2}$

c. Area kerja konstruksi kayu $64 \mathrm{~m}^{2}$

d. Ruang penyimpanan dan instruktur $48 \mathrm{~m}^{2}$

Namun menurut hasil pene-litian di SMK N 5 hanya mempunyai 2 ruang bengkel kayu yang biasa digunakan yaitu ruang bengkel kerja kayu tangan dan ruang bengkel kerja kayu mesin. Dan dalam hasil dokumentasi terdapat perbedaan ukuran luas ruang bengkel kayu antara dokumentasi luas ruang dan kenyataan dilapangan, yang meliputi 2 hal yaitu:

1. Dalam dokumen ukuran luas area kerja tangan mempunyai panjang $12 \mathrm{~m}$ dan lebar $20 \mathrm{~m}$, maka pada kenyataannya ukuran luas area kerja tangan yaitu panjang $14 \mathrm{~m}$ dan lebar $12 \mathrm{~m}$.

2. Lalu ukuran luas area kerja stasioner (mesin) dalam dokumen mempunyai panjang $12 \mathrm{~m}$ dan lebar $18 \mathrm{~m}$, sedangkan pada kenyataannya memiliki panjang $16 \mathrm{~m}$ dan lebar $15 \mathrm{~m}$.

Selanjutnya merupakan gambar suasana yang ada pada ruang bengkel kayu mesin dan ruang bengkel kayu tangan sebagai berikut:

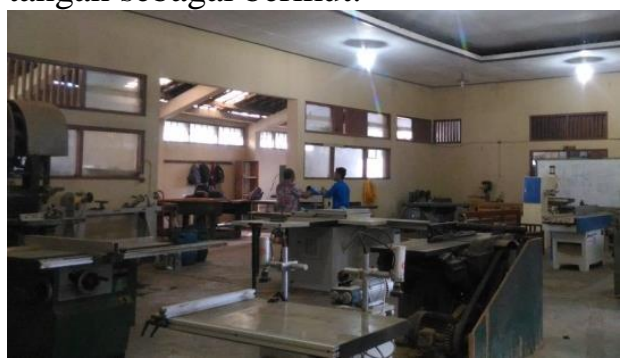

Gambar 2. Suasana ruang bengkel kayu mesin 


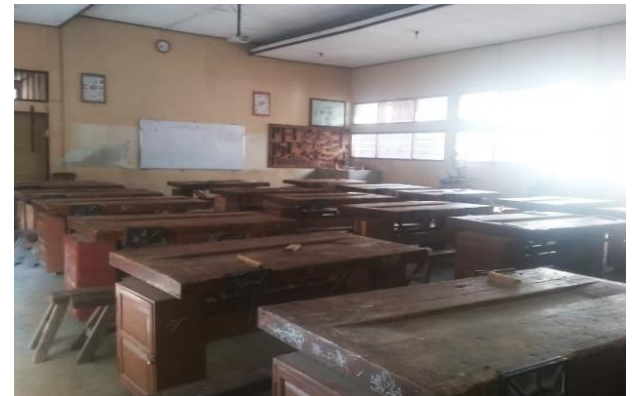

Gambar 3. Suasana ruang bengkel kayu tangan

Sehingga dapat disimpulkan bahwa luas ruang bengkel kerja kayu Program Keahlian Konstruksi Kayu di SMK N 5 Surakarta belum memenuhi standar dari Permendiknas No. 40 Tahun 2008, karena kapasitas pengguna melebihi kapasitas ruang yang ada yaitu: bengkel kerja kayu mesin adalah 8 perserta didik dan 16 peserta didik untuk bengkel kerja kayu tangan. Sedangkan pada kenyataannya pengguna ruang bengkel kerja kayu sekitar 30-35 peserta didik secara bersamaan.

2. Tata letak peralatan dan perabotan di ruang bengkel kerja kayu Program Keahlian Konstruksi Kayu sesuai dengan alur kerja praktik

Hasil observasi dan wawancara mengenai alur kerja praktik kayu di bengkel kerja kayu mesin menunjukkan bahwa alur kerja praktik kayu meliputi tahapan berikut:

a. Pertama peserta didik menyiapkan alat dan bahan yang akan digunakan dalam kegiatan praktik kayu.

b. Lalu peserta didik melakukan pemotongan kayu agar sesuai dengan ukuran yang diinginkan dan direncanakan sebelumnya. Pemotongan kayu ini meng-gunakan 2 jenis mesin gergaji yaitu gergaji potong dan gergaji belah. Penggunaan gergaji dapat menyesuaikan dengan kebutu-han peserta didik.

c. Masih melakukan pemotongan bahan agar menyesuaikan dengan ukuran yang diinginkan dengan cara mengetam atau meratakan permukaan kayu menggunakan mesin ketam, baik menggunakan mesin ketam penebal maupun mesin ketam perata.

d. Membuat sambungan pada kayu. Namun kayu harus diukur lalu dilukis (ditandai) terlebih dahulu agar dapat meminima-lisir kesalahan dan mendapat-kan ukuran yang tepat. Setelah itu membuat purus dan lubang dengan bantuan mesin bor, pahat, dan palu.

e. Setelah sambungan pada kayu sudah dibuat, maka peserta didik akan melakukan perakitan dan pengeleman atau pantek (perkuatan). Sekaligus melaku-kan finishing, seperti peng-amplasan, pelitur, dan peng-ecatan.

f. Setelah kegiatan pelajaran praktik selesai, peserta didik melakukan penyimpanan alat dan bahan, dan melakukan pembersihan disekitar area kerja.

Lalu kenyataan saat kegiatan praktik kayu berlangsung terdapat dua pilihan alur kerja praktik yang bisa digunakan. Namun hal ini menyababkan alur pekerjaan 1 dan alur pekerjaan 2 menjadi saling ber-tabrakan, ditambah lagi perletakan yang tidak sesuai dengan alur kerja praktik kayu dan banyak mesin yang tidak dapat digunakan namun masih disimpan di dalam ruang bengkel kerja kayu mesin. Sehingga membuat peserta didik melakukan praktik diluar ruangan atau lebih tepatnya di halaman depan ruang bengkel kerja kayu mesin, dapat dilihat pada gambar berikut:

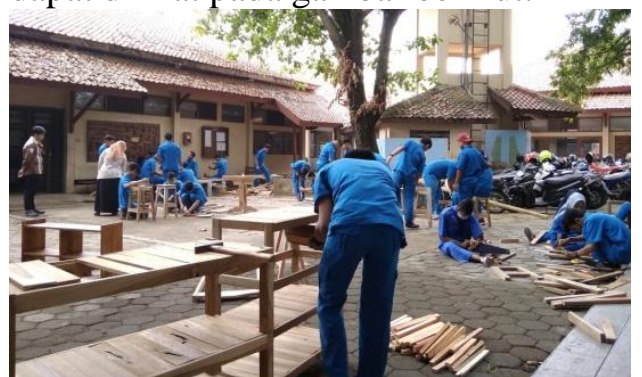

Gambar 4. Suasana kegiatan praktik kayu

Dari penjelasan diatas maka dapat disimpulkan bahwa tata letak peralatan dan perabotan yang ada di dalam ruang bengkel kerja mesin tidak sesuai dengan alur kerja praktik dan 
lebih mengarah kepada penyesuaian dengan ruangan yang ada.

3. Desain ruang dan tata letak peralatan/perabotan bengkel kerja kayu dengan kenyamanan penggunanya.

Hasil penelitian pada fokus 3 meliputi:

a. Jarak antar mesin satu dengan mesin yang lain dalam ruang bengkel kerja kayu mesin sekitar kurang lebih $2 \mathrm{~m}$ saja, yang seharusnya sekitar 3-5m, dan terdapat kelebihan (overload) mesin. Terlebih lagi banyak mesin rusak atau tidak terpakai yang masih disimpan dalam ruang bengkel kerja kayu mesin, dapat dilihat pada gambar dibawah ini:

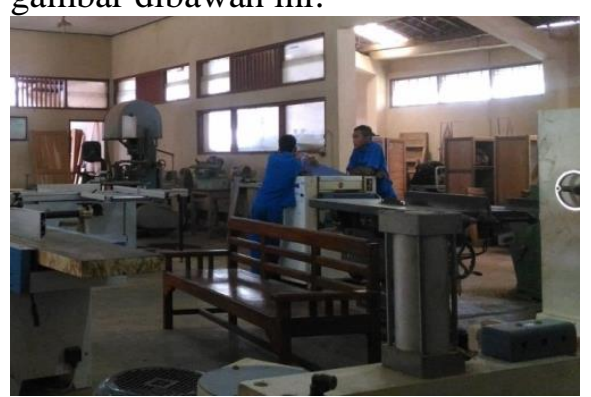

Gambar 5. Tata letak mesin dalam ruang bengkel kayu mesin

b. Ruang bengkel kerja kayu tangan yang seharusnya dapat digunakan sebagai tempat praktik malah digunakan sebagai tempat pembelajaran. Yang menyebabkan penggunaan mesin harus dilakukan bergantian dan banyak peserta didik yang memilih praktik diluar. Hal ini dapat dilihat pada gambar berikut:

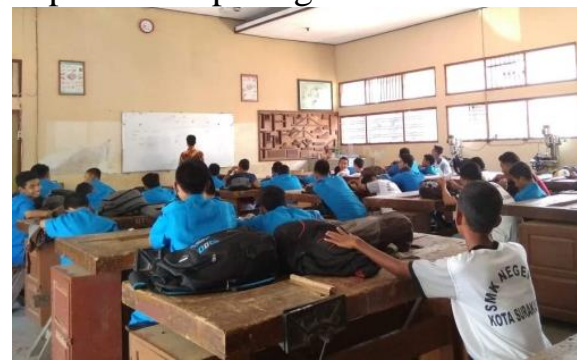

Gambar 6. Suasana kegiatan pembelajaran dalam ruang bengkel kerja kayu tangan

Maka dapat ditarik kesimpulan bahwa kenyamanan dalam melakukan praktik, dirasakan kurang nyaman, karena keterbatasan tempat, sirkulasi udara yang kurang baik, dan pembiasaan melakukan praktik diluar ruangan. Lalu dalam aspek ketinggian meja kerja mesin sudah disesuaikan tujuan ergonomi pemakainya, yang sudah merupakan penyesuaian dari pabrik.

\section{KESIMPULAN DAN SARAN}

A. Kesimpulan

Berdasarkan dari pembahasan 3 masalah fokus penelitian meliputi:

1) Luas ruang bengkel kerja kayu di SMK N 5 Surakarta belum memenuhi standar Permendiknas No. 40 Tahun 2008, karena jumlah peserta didik yang menggunakan ruang bengkel kayu melebihi kapasitas ruangnya.

2) Tata letak peralatan dan perabotan di ruang bengkel kerja kayu mesin belum sesuai dengan alur kerja praktik yang terdapat pada Usulan Standar Perletakan Peralatan/Perabotan dan Kenyamanan Pengguna di Bengkel Kerja Kayu SMK.

3) Desain ruang dan tata letak peralatan / perabotan belum memberikan kenyamanan bagi penggunanya, namun untuk ketinggian meja kerja pada mesin sudah dirasa nyaman. Hal ini ditinjau dari Usulan Standar Perletakan Peralatan/Perabotan dan Kenyamanan Pengguna di Bengkel Kerja Kayu SMK.

B. Saran

1) Bagi sekolah:

- Lebih memonitoring ruang bengkel.

- Berusaha untuk mengembangkan sarana dan prasarana.

2) Bagi guru:

- Lebih memahami fungsi dan standar apa yang digunakan pada ruang bengkel.

- Meningkatkan pengetahuan diri yang disesuaikan dengan perkembangan teknologi.

- Memberikan tindakan tegas bagi peserta didik yang tidak mengikuti peraturan. 
- Membagi peserta didik menjadi beberapa kelompok sehingga kegiatan praktik kayu.

3) Bagi bengkel kerja kayu:

- Perlu diadakannya penjelasan tentang SOP saat melakukan kegiatan praktik.

- Redesain perletakan peralatan/perabotan.

- Memberikan penjelasan pada tiap mesin.

- Pengembalian fungsi ruang.

- Penambahan penutup atap pada bagian halaman yang sering digunakan untuk melakukan praktik.

4) Bagi peneliti:

- Perlu adanya penelitian lanjutan yang dilakukan secara luas agar dapat memperbaiki dan menyempurnakan penelitian terdahulu.

\section{DAFTAR PUSTAKA}

Aan Komariah dan Djam'an Satori. (2010). Metodologi Penelitian Kualitatif. Bandung: Alfabeta

Cevilla, Convelo G. dkk. (1993). Pengantar Metode Penelitian. Jakarta: Universitas Indonesia.

Hasan, Bachtiar. (2010). Perencanaan Pembelajaran Bidang Studi. Bandung: Pustaka Ramadhan.

Husaini Usman dan Purnomo Setia Akbar. 2000. Metode Penelitian Sosial. Jakarta: Bumi Aksara.

Makrifa, Auliya Isti. (2012). Evaluasi Tingkat Kelayakan Sarana dan Prasarana Ruang Praktik Kelompok Keahlian Teknik Bangunan di SMK Negeri 2 Yogyakarta sebagai Sekolah Bertaraf Internasional (SBI). Skripsi Program Studi Pendidikan Teknik Sipil dan Perencanaan, Universitas Negeri Yogyakarta. Yogyakarta: Universitas Negeri Yogyakarta.

Martanti, Silvia Eka. (2009). Kajian Besaran Ruang dan Penataan Peralatan Ruang Bengkel Pembelajaran di SMK Negeri 2 Yogyakarta Jurusan Bangunan. Skripsi Program Studi
Pendidikan Teknik Sipil dan Perencanaan, Universitas Negeri Yogyakarta. Yogyakarta: Universitas Negeri Yogyakarta.

Pertaturan Menteri. (2008). Lampiran Peraturan Menteri Pendidikan Nasional No. 40 Tahun 2008 Tanggal 31 Juli 2008 Standar Sarana dan Prasarana Sekolah Menengah Kejuruan/Madrasah Aliyah Kejuruan (SMK/MAK).

Pribadhini, Vira Ningrum. (2015). Studi Kelayakan Ruang dan Peralatan Bengkel Kerja Kayu Program Keahlian Konstruksi Kayu di SMK Negeri 3 Yogyakarta. Skripsi Program Studi Pendidikan Teknik Sipil dan Perencanaan, Universitas Negeri Yogyakarta. Yogyakarta: Universitas Negeri Yogyakarta.

Shanraiska, Juan. (2015). Kesesuaian Ruang Bengkel dan Peralatan Kerja Batu untuk Mendukung Pembelajaran Praktik Konstruksi Batu Jurusan Teknik Konstruksi Batu dan Beton di SMK Negeri 2 Klaten. Skripsi Program Studi Pendidikan Teknik Sipil dan Perencanaan, Universitas Negeri Yogyakarta. Yogyakarta: Universitas Negeri Yogyakarta.

Sugiyono. (2007). Memahami Penelitian Kualitatif. Bandung: Alfabeta.

Tobroni, Imam Suprayogo. (2001). Metode Penelitian Sosial Agama cet.1. Bandung : Remaja Rosdakarya. 